\title{
Frequency of Breast Cancer Surgery Related Arm Lymphedema at King Abdulaziz University Hospital 2008 - 2015, a Tertiary Center Experience, Jeddah, Saudi Arabia
}

\author{
Sabah S. Moshref' ${ }^{1}$, FRCS, Yasir S. Jamal' ${ }^{1}$ FRCS(I), FICS, Zuhoor K. Al Gaithy ${ }^{2}$, MD, FRCSI, \\ Shadi S. Alkhayyat ${ }^{3}$, MBBS, FRCPC, Basim A. Awan ${ }^{1}$, FRCSC, Mahmoud Fakiha ${ }^{4}$, MD, \\ DESC, Hossam Ammar ${ }^{1}$, CAB / PL S, EBPRS, Abdullah Bamashmos ${ }^{1}$, MBBCh, MSc Surgery, \\ Mawaddah Alrajraji ${ }^{1}$, MBBCh, Mohammad Abolhamayl ${ }^{1}$, MBBCh \\ ${ }^{1}$ Department of Surgery, Division of Plastic Surgery, ${ }^{2}$ Department of General Surgery, ${ }^{3}$ Department of \\ Medicine, Division of Oncology, Faculty of Medicine, King Abdulaziz University \\ ${ }^{4}$ Department of Surgery, Division of Plastic Surgery, Faculty of Medicine, University of Jeddah, \\ Jeddah, Saudi Arabia
}

\section{Correspondence}

Prof. Sabah S. Moshref

P.O. Box 80215, Jeddah 21589, Saudi Arabia

e.M: sabahmoshref@hotmail.com

Submission: 29 Jan. 2017

Accepted: 5 Mar. 2017

\section{Citation}

Moshref SS, Jamal YS, Al Gaithy ZK, Alkhayyat SS, Awan BA, Fakiha M, Ammar H, Bamashmos A, Alrajraji M, Abolhamayl M. Frequency of breast cancer surgery related arm lymphedema at King Abdulaziz University Hospital 2008 - 2015 a tertiary center experience, Jeddah, Saudi Arabia. JKAU Med Sci 2017; 24 (2): 17-28. DOI: 10.4197/Med. 24.2.3

\begin{abstract}
The purpose of this retrospective study was to investigate the frequency of breast cancer-related lymphedema at King Abdulaziz University Hospital and factors associated with it. Eighty-four breast cancer-related lymphedema patients were recruited from Plastic and Reconstruction Surgery Unit, King Abdulaziz University Hospital, Jeddah, Saudi Arabia after breast cancer treatment during the period from 2008 till 2015. According to the circumference difference between healthy and affected arm, lymphedema degree was categorized into mild (> 5-10\%), moderate (> 10-15\%) and severe (> 15\%). From a total of 598 patients who underwent breast cancer resection, $84(14.05 \%)$ patients developed breast cancerrelated lymphedema. In out of the 84 patients who developed arm lymphedema, the treatment was mostly modified radical mastectomy and radiotherapy ( $n=59,70.24 \%$ ); followed by lumpectomy plus axillary lymph node dissection and radiotherapy ( $n=18,21.43 \%)$, simple mastectomy $(n=5,5.95 \%)$ and lumpectomy with sentinel lymph node dissection and radiotherapy $(n=2,2.38 \%)$ with statistical significant difference between them $(P=0.0001)$. The frequency of lymphedema in our institution is $14.05 \%$. It is mostly moderate, appears during the 1st year after surgery in patients who underwent modified radical mastectomy and radiotherapy, aged more than 60 years and obese.
\end{abstract}

\section{Keywords}

Breast cancer related lymphedema; Sentinel lymph node biopsy; Mastectomy; Morbidity 


\section{Introduction}

ymphedema is a condition caused by a disruption of lymph transport. This perturbation leads to the accumulation of protein-rich fluid, resulting in swelling within the subcutaneous tissues of the affected body part ${ }^{[1]}$. The condition may be acute or chronic, transient or progressive. Lymphedema can generally be classified into primary and secondary etiologies. Primary lymphedema is rare with no known acquired causes. It develops from an insufficiency in the structure and/or function of the lymphatic system that is characterized by malfunction of the lymphatic system in keeping up with the lymph load demands of the affected body part $^{[2]}$. Secondary lymphedema is often caused by the disruption or compression of the lymphatic system resulting from tumors or their treatment. A recognized risk factor for secondary lymphedema is the surgical removal of axillary lymph nodes and/or radiation therapy to the axilla for breast cancer-related lymphedema (BCRL), which can result in swelling of the arm, hand, or adjacent trunk quadrant ${ }^{[3]}$.

About 12 million cancer survivors currently reside in the USA, and at least 2.5 million are female breast cancer survivors ${ }^{[4]}$. In recent decades, breast cancer mortality rates have declined. Meanwhile, breast cancer survivors continue to experience various challenges after cancer and its active treatment. One of the potentially debilitating complications experienced by breast cancer survivors is lymphedema. When the lymphatic system is damaged, fluid accumulates in the affected limb, leading to swelling, fibrosis, reduced range of motion (ROM), decreased function, and, in later stages, infection and pain ${ }^{[5]}$. Due to advancements in care and surgical techniques such as the sentinel lymph node biopsy (SLNB), incidence rates have decreased substantially, with a $5-8 \%$ incidence in patients who undergo SLNB and a $14-16 \%$ incidence in patients who undergo axillary lymph node dissection (ALND), including only levels I and $\|^{[6]}$. Reports on cohorts with longer follow up report incidence rates of lymphedema as high as $34-94 \% \%^{[1,7]}$ depending on the methods of lymphedema measurement and quantification. The condition may result in physical and psychological consequences, which can negatively impact a woman's quality of life (QOL) and compromise her emotional well-being. Lymphedema can physically impair arm function by limiting ROM, as well as causing feelings of pain, heaviness, and numbness in the upper extremity. Psychologically, women may have decreased self-confidence due to a disturbance in body image, and experience negative emotions such as anxiety, frustration, sadness, anger, and increased self-consciousness ${ }^{[8]}$.

This retrospective study aimed to record frequency of $B C R L$ in the breast cancer patients operated at King Abdulaziz University Hospital, Jeddah, Saudi Arabia during a seven year period from 2008 to 2015; also, to determine the cross tabulation between onset and severity of lymphedema and type of breast cancer related treatment.

\section{Patients and Methods}

Eighty-four patients with breast cancer surgery related lymphedema recruited to this retrospective study from Plastic and Reconstruction Surgery Unit, King Abdulaziz University Hospital, Jeddah, Saudi Arabia who underwent unilateral breast cancer treatment at our hospital from January 2008 to January 2015. This study met the requirements of the Declaration of Helsinki (2013) and was approved by the Local Ethics Committee of the King Abdulaziz University. Inclusion criteria of patients were women who had unilateral breast cancer treatment from more than six months; absence of active disease; absence of functional change in the affected limb before surgery, which could lead to swelling of the limb; and simulating or masking symptoms of lymphedema, such as bursitis, tendonitis, and work-related musculoskeletal disorders. Exclusion criteria were women with unilateral disease but less than six months duration from surgery; bilateral breast cancer; a history of previous surgery in the axilla or history of filariasis or lympho-venous alteration of the limb before surgery, those with known arterial or venous disease, history of recurrent infections, active rheumatic disease, history of organs transplantation, ulcers in the affected arm, or skin metastases.

The following variables were collected from the patient's medical record: Patient's age, body mass index (BMI), type of breast surgery, stage of disease, tumor size, number of axillary lymph nodes dissected, sentinel lymph node involvement, onset of swelling after surgery, degree of swelling severity, symptoms and signs, patient education about lymphedema and adjuvant therapy (radiotherapy and/or chemotherapy).

Diagnosis of lymphedema was made by comparison of circumferential difference between affected and contralateral limb. Circumferential measurement of affected limb is an easy, inexpensive 
method to diagnose and monitor limb lymphedema and it had been used by the American Physical Therapy Association classification of lymphedema. Measuring the circumference of affected limb was made at three determined anatomical landmarks (upper arm at $15 \mathrm{~cm}$ from the olecranon process, forearm at $10 \mathrm{~cm}$ difference from the olecranon process and middle of the hand) with the limb fixed at a parallel plane with the floor in comparison with the unaffected limb ${ }^{[0]}$. Measurements were taken keeping both the limbs in a similar position with $90^{\circ}$ elbow flexion. The difference between the affected limb and the contralateral limb was calculated and expressed as an absolute value and percentage difference. Diagnosis of lymphedema was considered if the circumference of affected limb is greater than the unaffected by $\geq 2 \mathrm{~cm}^{[10,11]}$. Difference between two-limb circumferences at any level of $\leq 3$ $\mathrm{cm}$ (> 5-10\%) was considered as mild lymphedema, from 3-5 cm (> 10-15\%) as moderate lymphedema and $\geq 5 \mathrm{~cm}(>15 \%)$ as severe lymphedema.

\section{Statistics Analysis}

Data analysis was made using IBM SPSS Statistics for Windows, Version 20 (IBM Corp., Armonk, NY USA). Data was expressed as mean \pm standard deviation or number (\%) as appropriate. Significant between nonparametric data was done using chi-square test and between related parametric parameters using paired student's " $t$ " test. Levels of significance was $\mathrm{P}<0.05$.

\section{Results}

The total number of patients with mastectomy were 598 cases, the types of breast surgery were mostly modified radical mastectomy (MRM) $+R T(n=189$, $31.60 \%)$, followed by lumpectomy +SLNB+RT $(n=187$, $31.27 \%)$, simple mastectomy $(n=120,20.07 \%)$ and lastly lumpectomy +ALND+RT $(n=102,17.06 \%)$. The patients who developed lymphedema were 59 (31.21\%) in $M R M+R T$, 18 (17.65\%) in lumpectomy+ALND+RT, 5 (4.17\%) in simple mastectomy, 2 (1.07\%) in lumpectomy+SLNB+RT (Table 1).

The age group in BCRL patients was mostly $\geq 60$ years $(39.28 \%)$ then $40-49$ years, $50-59$ years, $30-$ 39 years and $20-29$ years $(29.76 \%, 23.81 \%, 5.95 \%$ and $1.19 \%$, respectively) with significant difference between them $(P=0.0001)$. Body mass index in $B C R L$ patients was mostly obese $(40.47 \%)$ followed by overweight $(17.86 \%)$ and normal weight (17.86\%) with significant difference between them $(P=0.009)$. The percentage of patient's education source about lymphedema by general surgery and reading how to prevent lymphedema were $11.90 \%$ and $7.14 \%$, respectively. The onset of swelling after surgery was mostly $6 \mathrm{~m}$ 1 year (60.72\%) followed by $1-2$ years, 2-3 years and $>3$ years $(9.52 \%, 2.38 \%$ and $2.38 \%$, respectively) with significance difference between them $(P=0.0001)$. The side of lymphedema was slightly more in left than right $\operatorname{arm}(51.19 \%$ vs. $48.81 \%, \mathrm{P}=0.827$ ) (Table 2 ).

The size of breast tumor was mostly $>3 \mathrm{~cm}$ (36.91\%) then $2.0-2.9 \mathrm{~cm},<1.5 \mathrm{~cm}$ and $1.6-1.9 \mathrm{~cm}$ $(17.86 \%, 11.90 \%, 8.33 \%$, respectively) with significant difference between them $(P=0.0001)$. Tumor stage was mostly stage $2(54.76 \%)$ then stage 3 , stage 1 and lastly stage $4(25.00 \%, 10.71 \%$ and $9.53 \%$, respectively) with significant difference between them $(P=0.0001)$. The percentage of ALND, SLNB, surgical and radiotherapy treatment and chemotherapy treatment were $(91.67 \%$, $53.57 \%, 69.05 \%$ and $97.62 \%$, respectively). The number of lymph nodes removed was mostly 1 - 10 nodes (28.57\%) then $\geq 16$ nodes, none, and $11-15$ nodes $(17.86 \%, 16.67 \%, 11.90 \%$, respectively) (Table 3$)$.

The patients presenting symptoms and signs were swelling $(73.81 \%)$; numbness $(50.00 \%)$; heaviness $(47.62 \%)$; pain $(40.48 \%)$; stiffness $(29.76 \%)$; itching (23.81\%); poor ROM (20.24\%); cellulitis (13.10\%);

Table 1. Incidence of lymphedema among different types of breast cancer treatment.

\begin{tabular}{|c|c|c|c|c|}
\hline \multirow{2}{*}{ Types of Breast Cancer Treatment } & \multirow{2}{*}{ Population } & \multicolumn{2}{|c|}{ Patients with Lymphedema } & \multirow{2}{*}{ Significance } \\
\hline & & Yes & No & \\
\hline $\mathrm{MRM}+\mathrm{RT}$ & $189(31.60 \%)$ & $59(31.21 \%)$ & $130(68.78 \%)$ & 0.0001 \\
\hline Lumpectomy+SLNB +RT & $187(31.27 \%)$ & $2(1.07 \%)$ & $185(98.93 \%)$ & 0.0001 \\
\hline Simple mastectomy & $120(20.07 \%)$ & $5(4.17 \%)$ & $115(95.83 \%)$ & 0.0001 \\
\hline Lumpectomy+ALND+RT & $102(17.06 \%)$ & $18(17.65 \%)$ & $84(82.35 \%)$ & 0.0001 \\
\hline Total & $598(100.00 \%)$ & $84(14.05 \%)$ & $514(85.95 \%)$ & 0.0001 \\
\hline
\end{tabular}


Frequency of Breast Cancer Surgery Related Arm Lymphedema at King Abdulaziz University Hospital... S.S. Moshref et al.

Table 2. Demographic and clinical characteristics of mastectomy patients with lymphedema $(n=84)$.

\begin{tabular}{|c|c|c|}
\hline Data & Number (\%) & Significance \\
\hline Age (years) & $55.43 \pm 12.24$ & \\
\hline Age Group & & 0.0001 \\
\hline $20-29$ years & $1(1.19 \%)$ & \\
\hline $30-39$ years & $5(5.95 \%)$ & \\
\hline $40-49$ years & $25(29.76 \%)$ & \\
\hline $50-59$ years & $20(23.81 \%)$ & \\
\hline$\geq 60$ years & $33(39.28 \%)$ & \\
\hline Body Mass Index $\left(\mathrm{kg} / \mathrm{m}^{2}\right)$ & $30.18 \pm 6.01$ & \\
\hline Body Mass Index Category & & 0.009 \\
\hline Normal $\left(18.50-24.90 \mathrm{~kg} / \mathrm{m}^{2}\right)$ & $15(17.86 \%)$ & \\
\hline Overweight $\left(25.00-29.90 \mathrm{~kg} / \mathrm{m}^{2}\right)$ & $15(17.86 \%)$ & \\
\hline Obese $\left(\geq 30 \mathrm{~kg} / \mathrm{m}^{2}\right)$ & $34(40.47 \%)$ & \\
\hline Missing & $20(23.81 \%)$ & \\
\hline \multicolumn{3}{|l|}{ Source of Education } \\
\hline By General Surgery Doctor & $10(11.90 \%)$ & \\
\hline Reading How to Prevent Lymphedema & $6(7.14 \%)$ & \\
\hline Onset of Swelling After Surgery & & 0.0001 \\
\hline $6 \mathrm{~m}-1$ year & $51(60.72 \%)$ & \\
\hline 1 year -2 years & $8(9.52 \%)$ & \\
\hline 2 years -3 years & $2(2.38 \%)$ & \\
\hline$>3$ years & $2(2.38 \%)$ & \\
\hline Didn't report swelling & $21(25.00 \%)$ & \\
\hline Side & & 0.827 \\
\hline Right & $41(48.81 \%)$ & \\
\hline Left & $43(51.19 \%)$ & \\
\hline
\end{tabular}

recurrent cellulitis (5.95\%); and wound infection (3.57\%). The degree of lymphedema was mostly moderate $(50.00 \%)$ then severe $(27.38 \%)$ and lastly mild (22.62\%) with significant difference between them $(P=$ 0.005). The mean of absolute circumferential difference pretreatment was $5.36 \mathrm{~cm}$ (Table 4).

The pretreatment circumferential size was significantly higher than contralateral upper limb size of mid-arm, forearm and mid-hand ( $P=0.0001$, for all). In all the patients, the mean of percentage difference between pretreatment and contralateral limb size of mid-arm, forearm and mid-hand were 11.42, 15.91 and 9.49, respectively (Table 5 ).

The age of edema appearance after surgery, in MRM+RT was mostly 6 months -1 year (59.32\%) then 1-2 years, $2-3$ years and $>3$ years $(11.87 \%, 3.39 \%$ and $1.69 \%$, respectively) with significant difference between them $(P=0.0001)$; in lumpectomy+ALND+RT was mostly 6 months - 1 year $(77.78 \%)$ then $1-2$ years $(5.55 \%)$ with significant difference between them $(P=0.019)$; in simple mastectomy was 6 months - 1 year $(20.00 \%)$; in
lumpectomy+SLNB+RT was 6 months - 1 year (50.00\%). The percentage of patients who didn't report swelling in $M R M+R T$, lumpectomy+ALND+RT, simple mastectomy and lumpectomy+SLNBI+RT were $23.73 \%, 16.67 \%$, $80.00 \%, 50.00 \%$, respectively. The degree of swelling after surgery, in MRM+RT was mostly moderate, then severe and mild with significant difference between them $(52.54 \%$ then $28.81 \%$ and $18.65 \%$, respectively; $\mathrm{P}=0.005)$; in lumpectomy+ALND+RT was mostly moderate, then severe and mild with insignificant difference between them $(55.55 \%$ then $27.78 \%$ and $16.67 \%$, respectively; $P=0.115)$; in simple mastectomy was mostly mild then severe with insignificant difference between them $(80.00 \%$ then $20.00 \%, P=$ 0.180 ); in lumpectomy+SLNB+RT was equally mild and moderate with insignificant difference between them (50.00\% and $50.00 \%, P=1.000$ ) (Table 6)

\section{Discussion}

With the transformation of breast cancer into a chronic disease, there is a greater emphasis on quality of life 
Frequency of Breast Cancer Surgery Related Arm Lymphedema at King Abdulaziz University Hospital... S.S. Moshref et al.

Table 3. Risk factors of lymphedema in the patients $(n=84)$.

\begin{tabular}{|c|c|c|}
\hline Data & Number (\%) & Significance \\
\hline Tumor Size & & 0.0001 \\
\hline$<1.5 \mathrm{~cm}$ & $10(11.90 \%)$ & \\
\hline $1.6-1.9 \mathrm{~cm}$ & $7(8.33 \%)$ & \\
\hline $2.0-2.9 \mathrm{~cm}$ & $15(17.86 \%)$ & \\
\hline$>3 \mathrm{~cm}$ & $31(36.91 \%)$ & \\
\hline Not Available & $21(25.00 \%)$ & \\
\hline Tumor Staging & & 0.0001 \\
\hline Stage 1 & $9(10.71 \%)$ & \\
\hline Stage 2 & $46(54.76 \%)$ & \\
\hline Stage 3 & $21(25.00 \%)$ & \\
\hline Stage 4 & $8(9.53 \%)$ & \\
\hline Axillary Lymph Node Dissection & & 0.0001 \\
\hline Yes & $77(91.67 \%)$ & \\
\hline No & $7(8.33 \%)$ & \\
\hline Number of Lymph Nodes Removed & & 0.0001 \\
\hline $1-10$ nodes & $24(28.57 \%)$ & \\
\hline $11-15$ nodes & $10(11.90 \%)$ & \\
\hline$>16$ nodes & $15(17.86 \%)$ & \\
\hline None & $14(16.67 \%)$ & \\
\hline Not Documented & $21(25.00 \%)$ & \\
\hline Sentinel Lymph Node Biopsy & & 0.0001 \\
\hline Yes & $45(53.57 \%)$ & \\
\hline No & $5(5.95 \%)$ & \\
\hline Not Documented & $34(40.48 \%)$ & \\
\hline Surgical and Radiotherapy Treatment & & 0.0001 \\
\hline Yes & $58(69.05 \%)$ & \\
\hline No & $26(30.95 \%)$ & \\
\hline Chemotherapy Treatment & & 0.0001 \\
\hline Yes & $82(97.62 \%)$ & \\
\hline No & $2(2.38 \%)$ & \\
\hline
\end{tabular}

Significance was made using chi-square test.

Table 4. Characteristics of patients with breast cancer related lymphedema $(n=84)$.

\begin{tabular}{|l|c|c|}
\hline \multicolumn{1}{|c|}{ Data } & Number (\%) & Significance \\
\hline Symptoms and Signs & & - \\
\hline Swelling & $62(73.81 \%)$ & \\
\hline Numbness & $42(50.00 \%)$ & \\
\hline Heaviness & $40(47.62 \%)$ & \\
\hline Pain & $34(40.48 \%)$ & \\
\hline Stiffness & $25(29.76 \%)$ & \\
\hline Itching & $20(23.81 \%)$ & \\
\hline Poor Range of Motion & $17(20.24 \%)$ & \\
\hline Cellulitis & $11(13.10 \%)$ & \\
\hline Recurrent Cellulitis & $5(5.95 \%)$ & \\
\hline Wound Infections & $3(3.57 \%)$ & $\mathbf{0 . 0 0 5}$ \\
\hline Absolute Circumferential Difference Pretreatment (cm) & $5.36 \pm 3.09$ & \\
\hline Degree of Lymphedema Pre-Operative & & \\
\hline Mild & $19(22.62 \%)$ & \\
\hline Moderate & $42(50.00 \%)$ & \\
\hline Severe & $23(27.38 \%)$ & \\
\hline
\end{tabular}

Statistics made using chi-square test 
Frequency of Breast Cancer Surgery Related Arm Lymphedema at King Abdulaziz University Hospital... S.S. Moshref et al.

Table 5. Comparison of pretreatment circumferential limb measurement with contralateral limb at different points.

\begin{tabular}{|l|c|c|c|}
\hline \multicolumn{1}{|c|}{ Data } & Mid-Arm & Forearm & Mid-Hand \\
\hline Pretreatment $(\mathrm{cm})$ & $35.64 \pm 5.83$ & $27.00 \pm 4.84$ & $20.15 \pm 2.40$ \\
\hline Contralateral Side (cm) & $31.72 \pm 5.53$ & $22.54 \pm 3.40$ & $18.51 \pm 1.94$ \\
\hline Significance & $\mathbf{0 . 0 0 0 1}$ & $\mathbf{0 . 0 0 0 1}$ & $\mathbf{0 . 0 0 0 1}$ \\
\hline \% Different (\%) & $11.42 \pm 7.61$ & $15.91 \pm 9.27$ & $9.49 \pm 8.17$ \\
\hline
\end{tabular}

Table 6. Cross tabulation between types of breast surgery and onset and degree of edema in 84 patients of BCRL.

\begin{tabular}{|c|c|c|c|c|}
\hline Data & \multicolumn{4}{|c|}{ Type of Breast Cancer Surgery } \\
\hline Onset of Edema & $\begin{array}{c}\text { MRM+RT } \\
(n=59,70.24 \%)\end{array}$ & $\begin{array}{c}\text { Lumpectomy + ALND+RT } \\
(\mathrm{n}=18,21.43 \%)\end{array}$ & $\begin{array}{c}\text { Simple Mastectomy } \\
(n=5,5.95 \%)\end{array}$ & $\begin{array}{c}\text { Lumpectomy +SLNB+RT } \\
(\mathrm{n}=2,2.38 \%)\end{array}$ \\
\hline 6 months - 1 year & $35(59.32 \%)^{*}$ & $14(77.78 \%)^{*}$ & $1(20.00 \%)^{*}$ & $1(50.00 \%)^{*}$ \\
\hline $1-2$ years & $7(11.86 \%)$ & $1(5.55 \%)$ & - & - \\
\hline $2-3$ years & $2(3.39 \%)$ & - & - & - \\
\hline$>3$ years & $1(1.69 \%)$ & - & - & - \\
\hline Didn't report swelling & $14(23.73 \%)$ & $3(16.67 \%)$ & $4(80.00 \%)$ & $1(50.00 \%)$ \\
\hline Significance & 0.0001 & 0.019 & 0.180 & 1.000 \\
\hline \multicolumn{5}{|l|}{ Degree of Edema } \\
\hline Mild & $11(18.65 \%)$ & $3(16.67 \%)$ & $4(80.00 \%)$ & $1(50.00 \%)$ \\
\hline Moderate & $31(52.54 \%)$ & $10(55.55 \%)$ & $0(0.00 \%)$ & $1(50.00 \%)$ \\
\hline Severe & $17(28.81 \%)$ & $5(27.78 \%)$ & $1(20.00 \%)$ & $0(0.00 \%)$ \\
\hline Significance & 0.005 & 0.115 & 0.180 & 1.000 \\
\hline
\end{tabular}

Statistics made using chi-square test.

MRM: Modified radical mastectomy; RT: Radiotherapy; ALND: Axillary Iymph node dissection; SLNB: Sentinel lymph node biopsy.

*The percentage is out of the 84 patients with BCRL

(QOL) and long-term post treatment sequelae. There is an expectation on the part of patients, their families and caregivers that the patient should lead a near normal life style. Except for breast cancer recurrence, no event is more dreaded than the development of lymphedema.

The results of present study revealed that frequency of $B C R L$ in patients with unilateral breast cancer was $14.05 \%$. The incidence of breast cancerrelated lymphedema varies greatly in the literature, ranging from $2 \%$ to $83 \%{ }^{[12,13]}$. This wide range in incidences is attributed to more than one factor. There is no clear and universal definition of lymphedema and there are variations in the methods of its diagnosis and measurement. Some methods depend on circumference measurements, but other methods exist, including water displacement, bioelectrical impedance, or bioimpedance spectroscopy which reflects increased water content ${ }^{[14]}$. Since those tests do not completely agree with each other the results are expected to be different ${ }^{[14]}$.

Perimetry, which was the diagnostic method used in this study, is based on comparing the measurement of the circumference of the affected arm with the contralateral $\operatorname{arm}^{[10,11]}$. Although water displacement and circumference measurement are both reliable techniques in clinical practice, the use of arm circumferences is the most popular method for assessing lymphedema. This is probably related to its simplicity and practicality. Hayes et al., ${ }^{[12]}$ found that, compared with bioimpedance spectroscopy, $40 \%$ to $60 \%$ of patients measured with circumferential or selfreport tools went undetected. Further, a false diagnosis of lymphedema was given to $12 \%$ of those diagnosed using circumferential tools and $40 \%$ of those using selfreport instruments.

Despite the numerous publications in the literature, the precise definition of lymphedema is still debated, leading to confusion regarding the presence of "clinically significant" lymphedema. In this study, diagnosis of lymphedema was considered if the circumference of affected limb is greater than the unaffected limb by $\geq 2 \mathrm{~cm}$. Difference between two-limb circumferences at any level of $\leq 3 \mathrm{~cm}$ was taken as mild lymphedema, from $3-5 \mathrm{~cm}$ as moderate lymphedema and $\geq 5 \mathrm{~cm}$ as severe lymphedema. In all the patients, the degree of lymphedema in this study were mostly moderate $(50.00 \%)$ followed by severe $(27.38 \%)$ and lastly mild (22.62\%). In cases of 
$M R M+R T$ and lumpectomy+ALND+RT, the degree of lymphedema was mostly moderate, while in cases of simple mastectomy was mostly mild. Some practitioners consider a maximum girth difference of $\geq$ $2 \mathrm{~cm}$ or a volume difference of $\geq 200 \mathrm{~mL}$ in the involved limb compared to the uninvolved limb to indicate a diagnosis of lymphedema ${ }^{[15]}$.

Another factor explaining the varying incidence of lymphedema is related to the fact that patients are evaluated at different time periods following their surgery. Although lymphedema usually develops within the first 2-3 years after surgery, it is well known that it can develop many years later ${ }^{[16]}$. Our results indicate that most lymphedema (59.32\%) occurred within $6 \mathrm{~m}$ - 1 year after breast surgery followed by 1 year -2 years (11.87\%), $2-3$ years (3.39\%) and $>3$ years (1.69\%). Other series showed that $75-80 \%$ of patients who develop lymphedema do so within the first or second year after surgery ${ }^{[10]}$. Approximately $10 \%$ of patients developed lymphedema after the third year ${ }^{[10]}$. Data from Armer and Stewart's 60-month follow-up demonstrated that cases of lymphedema continued to develop at five years ${ }^{[7]}$. In a six-year follow-up, Hayes et al ${ }^{[1]}$ reported some new cases at that time, albeit much less than in the first 2 years ${ }^{[1]}$. The risk of developing lymphedema lasts for a lifetime ${ }^{[7]}$, so this sense of vulnerability can be difficult for many patients to overcome. So, more frequent surveillance throughout this time (e.g., once every 3-6 months) seems reasonable ${ }^{[17]}$. In attempting to reestablish the lymphovenous balance of the upper limb and breast region after breast cancer treatment, the body makes use of compensatory mechanisms, which attempt to avoid edema. However, some factors such as trauma, aging, and repetitive or non-repetitive episodes of infections can overwhelm the lymphatic system, changing the balance. Therefore, the longer the time elapsed since surgery, the greater the risk of developing lymphedema ${ }^{[11]}$.

Effective identification of the risk factors for the development of breast cancer related lymphedema is fundamental for the prevention, early diagnosis and management. Patients also differ in stage and grade of their disease, and in the adjuvant treatment received. Patients with more advanced tumors usually receive more aggressive treatment, including mastectomy, axillary dissection, and radiotherapy, which have been shown in different studies to be associated with increased risk of lymphedema ${ }^{[12,18]}$. In our series, 59 (31.21\%) out of 189 breast cancer patients developed lymphedema after modified radical mastectomy and radiotherapy, 18 (17.65\%) of 102 patients developed lymphedema after lumpectomy, ALND and radiotherapy, five $(4.17 \%)$ of 120 patients developed lymphedema after simple mastectomy, two $(1.07 \%)$ of 187 patients developed lymphedema after lumpectomy, SLNB and radiotherapy. The most frequently-cited risk factor for lymphedema secondary

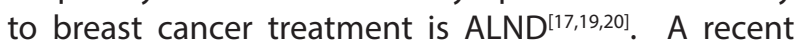
meta-analysis indicated that women who underwent ALND as part of their surgical treatment for breast cancer had a 4-times higher incidence of lymphedema compared with those who underwent SLNB (19.9\% vs. $5.6 \%$, respectively $)^{[17]}$. Other articles reported incidence rates of $33 \%$ to $48 \%$ of lymphedema developed after ALND and radiation therapy ${ }^{[21]}$ and $5 \%$ to $14 \%$ after sentinel node biopsy and radiotherapy ${ }^{[22]}$. Say and Donegen ${ }^{[23]}$ reported that simple mastectomy without axillary dissection carried an incidence of $9.1 \%$ of lymphedema compared to $31.5 \%$ in patients following modified radical mastectomy. Schünemann and Willich ${ }^{[24]}$ reported a lymphedema prevalence of $39 \%$ following radical mastectomy, 24\% following modified radical mastectomy and $9 \%$ following breast conservation surgery. Also, Nesvold and co-workers ${ }^{[25]}$ reported that secondary lymphedema was more prevalent in patients who had radical mastectomy (27\%) than in breast-conserving surgery (8\%) and in SLNB (3\%). Meanwhile, some authors had noted that that the extent or level of axillary node dissection does not show statistically significant association with the risk of development of lymphedema ${ }^{[26]}$.

Additional lymphedema risk factors that have been suggested include, higher BMI or obesity, experience of the surgeon, dominant limb, nodal radiation, mastectomy, number of lymph nodes removed and number of positive lymph nodes, presence of extra capsular spread, size and grade of the primary tumor, co-morbid conditions, adjuvant chemotherapy, and decreased physical activity levels $s^{[12,17-19,25,27,28]}$.

Patient characteristics have been evaluated as risk factors such as high BMI, age at diagnosis, hypertension, history of infection and inflammation, handedness and excessive use of limb ${ }^{[29]}$ In this study, the mean age of the patients was 55.43 years, the patient's age group who BCRL was mostly in $\geq 60$ years (39.28\%) followed by $40-49$ years $(29.76 \%), 50-59$ years $(23.81 \%), 30-39$ years $(5.95 \%)$ and lastly $20-29$ years $(1.19 \%)$. Age is a variable often associated with lymphedema ${ }^{[28,30]}$. Along with the aging process, anatomical and physiological changes related to lymphatic obstruction occur, which 
may predispose to the development of lymphedema, with the main mechanism being the opening of lympho-venous anastomoses ${ }^{[19]}$. The higher incidence of lymphedema in older patients observed in some studies $^{[31]}$ may be due to a progressive loss of these anastomoses because of the aging process ${ }^{[19]}$. Hayes et al. ${ }^{[12]}$ showed that age above 50 may increase the risk of lymphedema incidence to 3.3 times. Meanwhile, a study by Yen et al. ${ }^{[30]}$ who investigated self-reporting of the risk factors for lymphedema in older women, found no significant difference between women with and those without lymphedema. The difference in evaluation methods and the average age of the women involved in these studies may be responsible for the discrepancy of results.

In this study, the mean of BMI of BCRL patients was $30.10\left(\mathrm{~kg} / \mathrm{m}^{2}\right)$. Most of our patients were obese $(\mathrm{n}=$ $34,40.47 \%)$ followed by overweight $(n=15,17.86 \%)$, while normal weight was found in $15(17.86 \%)$ patients. The association between BMI and lymphedema has been approved in many studies ${ }^{[32,33]}$. Soran and coworkers ${ }^{[34]}$ believed that it is not clear whether obesity is a direct risk factor for arm edema; it is certainly a risk factor for infection and poor wound healing. Foldi et al. ${ }^{[35]}$ believes that lymphedema combined with obesity is more than the sum of the two diseases. So, they suggested that controlling $\mathrm{BMI}$ can be helpful in reducing lymphedema, even though it may not be a direct risk factor for $\mathrm{it}^{[18]}$.

In this study, the types of education about lymphedema among BCRL patients were by general surgery doctors $(11.90 \%)$ and reading how to prevent lymphedema (7.14\%). Lower incidences of lymphedema were found in women who exercised regularly, received lymphedema education before treatment, and performed preventive self-care activities $^{[18]}$. Bani et al., ${ }^{[36]}$ found that provision of education on lymphedema was associated with use of lymph-drainage massage services.

In our lymphedema patients, the percentage of patients with ALND was $91.67 \%$ and sentinel lymph node biopsy was $53.57 \%$. The number of lymph nodes removed was mostly 1 - 10 nodes (28.57\%) then $\geq 16$ nodes (17.86\%) and $11-15$ nodes (11.90\%). The size of breast tumor was mostly $>3 \mathrm{~cm}$ (36.91\%) then $2.0-2.9$ $\mathrm{cm}(17.86 \%),<1.5 \mathrm{~cm}(11.90 \%)$ and $1.6-1.9 \mathrm{~cm}(8.33 \%)$. The breast cancer stage was mostly stage 2 (54.76\%) then stage $3(25.00 \%)$, stage $1(10.71 \%)$ and lastly stage 4 (9.53\%). Many reports cited that vulnerability of lymphedema increases with the number of nodes excised, as well as with the number of positive nodes in the dissection ${ }^{[37]}$. Removal of lymph nodes, rather than type of lymph node surgery, may be more germane to risk of BCRL. In a retrospective study of 1,338 older breast cancer patients who were diagnosed with in situ and invasive cancer and self-reported having BCRL, an increased risk of BCRL was observed with successive removal of nodes but not with type of surgery ${ }^{[30]}$. In spite of many studies which had introduced the higher number of excised lymph nodes as a predictor of lymphedema ${ }^{[38-40]}$, in some valid studies only a higher number of involved lymph nodes or a higher stage of disease were noticed to be related to lymphedema ${ }^{[2,41]}$. Observational studies have documented a lower risk of $B C R L$ and other arm morbidity symptoms among patients who underwent SLNB only compared to $A L N D^{[26,42]}$. For example, Francis et al. ${ }^{[26]}$ observed a $16.8 \%$ incidence of BRCL after SLNB using the Common Terminology Criteria for Adverse Events (CTCAE) v3.0 criteria for diagnosis, compared to an increased risk of $47.1 \%$ after ALND. In contrast, no differences in risk at one year of follow-up were observed between women who underwent SLNB and ALND compared to SLNB alone in the American College of Surgeons Oncology Group (ACOSOG) randomized clinical trial ${ }^{[27]}$. Although the evidence is suggestive that SLNB compared to $A L N D$ is associated with lower risk of $B C R L^{[43]}$, likely due to fewer lymph nodes removed with SLNB, it was found that with even one removed node, a woman is at an increased risk (4.1\%) for BCRL. It is expected that by early diagnosis of breast cancer in lower stage, the incidence of lymphedema would decline.

The incidence of lymphedema in the current study in patients receiving postoperative radiotherapy with surgery was $69.05 \%$ and in patients receiving chemotherapy was $97.62 \%$. In this respect, Kissin et al. ${ }^{[44]}$ reported lymphedema incidence of $8.3 \%$ following radiotherapy alone and $38.3 \%$ with a combination of axillary dissection and radiotherapy. Radiotherapy is considered as a risk factor for development of lymphedema, mainly when axillary irradiation is applied ${ }^{[12,37]}$. Zhu et al. ${ }^{[45]}$ reported that radiation therapy doubles the risk, and chemotherapy contributes to the development of lymphedema. A likely explanation is the occurrence of lymphedema due to the blockage of lymph vessels or their compression by fibrosis caused by this treatment ${ }^{[31]}$. Hence following axillary dissection radiotherapy to axilla shouldn't be used judiciously and 
unnecessary over treatment of axilla. There has also been reference to lymphedema developing during treatment secondary to chemotherapy regimens ${ }^{[46]}$. The rationale for this association remains unclear and is a phenomenon that requires further study.

The detrimental effects of lymphedema on a breast cancer survivor's physical and psychosocial health can be overwhelming, particularly because lymphedema is a risk that lasts for the survivor's life time ${ }^{[47]}$. In this study, the symptoms and signs of lymphedema were mostly swelling (73.81\%) followed by numbness $(50.00 \%)$, heaviness $(47.62 \%)$, pain $(40.48 \%)$, stiffness (29.76\%), itching $(23.81 \%)$, poor ROM $(20.24 \%)$, cellulitis $(13.10 \%)$, recurrent cellulitis $(5.95 \%)$ and wound infection (3.57\%). Assessment of post-breast cancer lymphedema is largely dependent on the evaluation of subjective symptoms and objective signs. Changes in fit of jewelry/clothing, skin changes, decrease in ROM, and feelings of heaviness, pain, and swelling are all indicators of lymphedema ${ }^{[48]}$. In this respect, it had been reported that although women with lymphedema report a variety of physical symptoms, including pain, heaviness, tenderness, numbness, limited Range of Motion (ROM), and stiffness, arm swelling is the most common ${ }^{[49]}$. Pain is also a common symptom in lymphedema patients. For example, in Paskett and Stark's ${ }^{[50]}$ study $72 \%$ of the lymphedema patients reported pain in addition to edema, and $57 \%$ of them had intermittent pain, and Moffatt et al. ${ }^{[51]}$ showed that $50 \%$ of patients had experienced pain or discomfort from their edema. Verbelen et al ${ }^{[52]}$ reported that even after two years women with a negative SLNB complain of pain (range 5.6-51.1\%), numbness (range 5.1-51.1\%), loss of strength (range 0-57.7\%), decreased internal rotation $(44.4 \%)$, and decreased abduction (range $0-41.4 \%)$. Persons with lymphedema are especially at risk for cellulitis because of the presence of stagnant lymph fluid in the limbs creating ideal conditions for bacteria to thrive ${ }^{[37]}$. In addition to limitations, women with lymphedema are subject to potential psychosocial problems including depression, anxiety, poor adjustment to illness, and low self-esteem ${ }^{[49]}$.

In conclusion, the incidence of $B C R L$ in our hospital $(14.05 \%)$ is presently high in comparison with the most recent meta-analysis indicating the seriousness of this condition. Although most of our patients with lymphedema have moderate degree of severity, it is still associated with significant physical morbidity mostly swelling of affected limb. Old age of patients and obesity as well as surgical method, the extent of the axillary approach, radiotherapy, and chemotherapy, are associated with the presence of lymphedema. Close monitoring of breast cancer survivors in the first 3 years after breast cancer treatment is crucial for early detection and start lymphedema treatment measures as early as possible to decrease the development of progressive lymphedema which is a very devastating condition affecting the QOL of breast cancer survivors.

\section{Conflict of Interest}

The authors have no conflict of interest.

\section{Disclosure}

None of the authors received any type of commercial support either in forms of compensation or financial for this study. They have no financial interest in any of the products or devices, or drugs mentioned in this article.

\section{Ethical Approval}

Obtained.

\section{References}

[1] Hayes S, Di Sipio T, Rye S, López JA, Saunders C, Pyke C, Bashford J, Battistutta D, Newman B.. Prevalence and prognostic significance of secondary lymphedema following breast cancer. Lymphat Res Biol 2011; 9(3): 135141.

[2] Lawenda BD, Mondry TE, Johnstone PA. Lymphedema: a primer on the identification and management of a chronic condition in oncologic treatment. CA Cancer J Clin 2009; 59(1): 8-24

[3] Shah C, Arthur D, Riutta J, Whitworth P, Vicini FA. Breastcancer related lymphedema: a review of procedure-specific incidence rates, clinical assessment AIDS, treatment paradigms, and risk reduction. Breast J 2012; 18(4): 357361.

[4] Altekruse SF, Kosary CL, Krapcho M, Neyman N, Aminou R, Waldron W, Ruhl J, Howlader N, Tatalovich Z, Cho H, Mariotto A, Eisner MP, Lewis DR, Cronin K, Chen HS, Feuer EJ, Stinchcomb DG, Edwards BK (eds). SEER Cancer Statistics Review, 1975-2007, National Cancer Institute. Bethesda, MD, http://seer.cancer.gov/csr/1975_2007/, based on November 2009 SEER data submission, posted to the SEER web site, 2010.

[5] Ridner SH. Pathophysiology of lymphedema. Semin Oncol Nurs 2013; 29(1): 4-11.

[6] Miaskowski C, Dodd M, Paul SM, West C, Hamolsky D, Abrams G, Cooper BA, Elboim C, Neuhaus J, Schmidt 
BL, Smoot B, Aouizerat BE. Lymphatic and angiogenic candidate genes predict the development of secondary lymphedema following breast cancer surgery. PLoS One 2013; 8(4): e60164

[7] Armer JM, Stewart BR. Post-breast cancer lymphedema: incidence increases from 12 to 30 to 60 months. Lymphology 2010; 43(3): 118-127.

[8] O'Toole J, Jammallo LS, Skolny MN, Miller CL, Elliott K, Specht MC, Taghian AG. Lymphedema following treatment for breast cancer: a new approach to an old problem. Crit Rev Oncol Hematol 2013; 88(2): 437-446.

[9] Querci della Rovere G, Ahmad I, Singh P, Ashley S, Daniels IR, Mortimer P. An audit of the incidence of arm lymphoedema after prophylactic level I/II axillary dissection without division of the pectoralis minor muscle. Ann R Coll Surg Engl 2003; 85(3): 158-161.

[10] Norman SA, Localio AR, Potashnik SL, Simoes Torpey HA, Kallan MJ, Weber AL, Miller LT, Demichele A, Solin LJ. Lymphedema in breast cancer survivors: incidence, degree, time course, treatment, and symptoms. J Clin Oncol 2009; 27(3): 390-397.

[11] Hunt KK, Askew R, Cormier JN. Measuring lymphedema in patients with breast cancer: go with the flow? Breast Cancer Res Treat 2009; 117(3): 559-560.

[12] Hayes S, Janda M, Cornish B, Battistutta D, Newman B. Lymphedema secondary to breast cancer: how choice of measure influences diagnosis, prevalence, and identifiable risk factors. Lymphology 2008; 41(1): 18-28.

[13] Salonen P, Rantanen A, Kellokumpu-Lehtinen PL, Huhtala $H$, Kaunonen $M$. The quality of life and social support in significant others of patients with breast cancer--a longitudinal study. Eur J Cancer Care (Engl) 2014; 23(2): 274-283.

[14] Ward LC, Czerniec S, Kilbreath SL. Quantitative bioimpedance spectroscopy for the assessment of lymphoedema. Breast Cancer Res Treat 2009; 117(3): 541547.

[15] Armer JM, Stewart BR. A comparison of four diagnostic criteria for lymphedema in a post-breast cancer population. Lymphat Res Biol 2005; 3(4): 208-217.

[16] Ridings P, Bucknall TE. Modern trends in breast cancer therapy: towards less lymphedema? Eur J Surg Oncol 1998; 24(1): 21-22.

[17] DiSipio T, Rye S, Newman B, Hayes S. Incidence of unilateral arm lymphoedema after breast cancer: a systematic review and meta-analysis. Lancet Oncol 2013; 14(6): 500-515.

[18] Park JH, Lee WH, Chung HS. Incidence and risk factors of breast cancer lymphoedema. J Clin Nurs 2008; 17(11): 1450-1459.

[19] Norman SA, Localio AR, Kallan MJ, Weber AL, Torpey HA, Potashnik SL, Miller LT, Fox KR, DeMichele A, Solin LJ. Risk factors for lymphedema after breast cancer treatment. Cancer Epidemiol Biomarkers Prev 2010; 19(11):27342746.
[20] Yang EJ, Park WB, Seo KS, Kim SW, Heo CY, Lim JY. Longitudinal change of treatment-related upper limb dysfunction and its impact on late dysfunction in breast cancer survivors: a prospective cohort study. J Surg Oncol 2010; 101(1): 84-91.

[21] Beaulac SM, McNair LA, Scott TE, LaMorte WW, Kavanah MT. Lymphedema and quality of life in survivors of early-stage breast cancer. Arch Surg 2002; 137(11): 1253-1257.

[22] Armer J, Fu MR, Wainstock JM, Zagar E, Jacobes LK. Lymphedema following breast cancer treatment, including sentinel lymph node biopsy. Lymphology 2004; 37(2): 7391.

[23] Say CC, Donegen W. A biostatistical evaluation of complications from mastectomy. Surg Gynaecol Obstet 1974; 138: 370-376.

[24] Schünemann $H$, Willich N. Lymphedema of the arm after primary treatment of breast cancer. Anti Cancer Res 1998; 18(3C): 2235-2236

[25] Nesvold IL, Dahl AA, Løkkevik E, Marit Mengshoel A, Fosså SD. Arm and shoulder morbidity in breast cancer patients after breast-conserving therapy versus mastectomy. Acta Oncol 2008; 47(5): 835-842.

[26] Francis WP, Abghari P, Du W, Rymal C, Suna M, Kosir MA. Improving surgical outcomes: standardizing the reporting of incidence and severity of acute lymphedema after sentinel lymph node biopsy and axillary lymph node dissection. Am J Surg 2006; 192(5): 636-639.

[27] Lucci A, McCall LM, Beitsch PD, Whitworth PW, Reintgen DS, Blumencranz PW, Leitch AM, Saha S, Hunt KK, Giuliano AE; American College of Surgeons Oncology Group. Surgical complications associated with sentinel lymph node dissection (SLND) plus axillary lymph node dissection compared with SLND alone in the American College of Surgeons Oncology Group Trial Z0011. J Clin Oncol 2007; 25(24): 3657-3663.

[28] Tsai RJ, Dennis LK, Lynch CF, Snetselaar LG, Zamba GK, ScottConner $C$. The risk of developing arm lymphedema among breast cancer survivors: a meta-analysis of treatment factors. Ann Surg Oncol 2009; 16(7): 1959-1972.

[29] Togawa K, Ma H, Sullivan-Halley J, Neuhouser ML, Imayama I, Baumgartner KB, Smith AW, Alfano CM, McTiernan A, Ballard-Barbash R, Bernstein L. Risk factors for self-reported arm lymphedema among female breast cancer survivors: a prospective cohort study. Breast Cancer Res 2014; 16(4): 414.

[30] YenTW, Fan X, Sparapani R, Laud PW, Walker AP, Nattinger AB. A contemporary, population-based study of lymphedema risk factors in older women with breast cancer. Ann Surg Oncol 2009; 16(4): 979-988.

[31] Clough-Gorr KM, Ganz PA, Silliman RA. Older breast cancer survivors: factors associated with self-reported symptoms of persistent lymphedema over 7 years of follow-up. Breast J 2010; 16(2): 147-155.

[32] Clark B, Sitzia J, Harlow W. Incidence and risk of arm oedema 
following treatment for breast cancer: a three-year followup study. QJM 2005; 98(5): 343-348.

[33] Forner-Cordero I, Muñoz-Langa J, Forner-Cordero A, DeMiguel-Jimeno JM. Predictive factors of response to decongestive therapy in patients with breast-cancerrelated lymphedema. Ann Surg Oncol 2010; 17(3): 744751.

[34] Soran A, D'Angelo G, Begovic M, Ardic F, Harlak A, Samuel Wieand $H$, Vogel VG, Johnson RR. Breast cancer-related lymphedema--what are the significant predictors and how they affect the severity of lymphedema? Breast J 2006; 12(6): 536-543.

[35] Földi M, Földi E, Kubik S. Text Book of Lymphology for Physicians and Lymphedema Therapists. $1^{\text {st }}$ edn. Munchen, Bavaria: Urban \& Fischer, 2003.

[36] Bani HA, Fasching PA, Lux MM, Rauh C, Willner M, Eder I, Loehberg C, Schrauder M, Beckmann MW, Bani MR. Lymphedema in breast cancer survivors: assessment and information provision in a specialized breast unit. Patient Educ Couns 2007; 66(3): 311-318.

[37] Bevilacqua JL, Kattan MW, Changhong Y, Koifman S, Mattos IE, Koifman RJ, Bergmann A. Nomograms for predicting the risk of arm lymphedema after axillary dissection in breast cancer. Ann Surg Oncol 2012; 19(8): 2580-2589.

[38] Paskett ED, Naughton MJ, McCoy TP, Case LD, Abbott JM. The epidemiology of arm and hand swelling in premenopausal breast cancer survivors. Cancer Epidemiol Biomarkers Prev 2007; 16(4): 775-782.

[39] Meeske KA, Sullivan-Halley J, Smith AW, McTiernan A, Baumgartner KB, Harlan LC, Bernstein L. Risk factors for arm lymphedema following breast cancer diagnosis in Black women and White women. Breast Cancer Res Treat 2009; 113(2): 383-391.

[40] Goldberg Jl, Riedel ER, Morrow M, Van Zee KJ. Morbidity of sentinel node biopsy: relationship between number of excised lymph nodes and patient perceptions of lymphedema. Ann Surg Oncol 2011; 18(10): 2866-2872.

[41] Deo SV, Ray S, Rath GK, Shukla NK, Kar M, Asthana S, Raina $V$. Prevalence and risk factors for development of lymphedema following breast cancer treatment. Indian J Cancer 2004; 41(1): 8-12.

[42] Helms G, Kühn T, Moser L, Remmel E, Kreienberg R. Shoulder-arm morbidity in patients with sentinel node biopsy and complete axillary dissection - data from a prospective randomised trial. Eur J Surg Oncol 2008; 35(7): 696-701.

[43] Cochran AJ, Roberts AA, Saida T. The place of lymphatic mapping and sentinel node biopsy in oncology. Int J Clin Oncol 2003; 8(3): 139-150.

[44] Kissin MW, Querci della Rovere G, Easton D, Westbury G. Risk of lymphedema following the treatment of breast cancer. Br J Surg 1986; 73(7): 580-584.

[45] Zhu YQ, Xie YH, Liu FH, Guo Q, Shen PP, Tian Y. Systemic analysis on risk factors for breast cancer related lymphedema. Asian Pac J Cancer Prev 2014; 15(16): 65356541.

[46] Ohsumi S, Shimozuma K, Ohashi Y, Takeuchi A, Suemasu K, Kuranami M, Ohno S, Watanabe T. Subjective and objective assessment of edema during adjuvant chemotherapy for breast cancer using taxane-containing regimens in a randomized controlled trial: The National Surgical Adjuvant Study of Breast Cancer 02. Oncology 2012; 82(3): 131-138.

[47] Bernas MJ, Askew RL, Armer JM, Cormier JN. Lymphedema: how do we diagnose and reduce the risk of this dreaded complication of breast cancer treatment? Current Breast Cancer Reports 2010; 2(1): 53-58.

[48] Rockson SG, Miller LT, Senie R, Brennan MJ, Casley-Smith JR, Földi E, Földi M, Gamble GL, Kasseroller RG, Leduc A, Lerner R, Mortimer PS, Norman SA, Plotkin CL, RinehartAyres ME, Walder AL. Diagnosis and management of lymphedema. Cancer 1998; 83(12 Suppl American): 2882-2885.

[49] Thomas-MacLean R, Miedema B, Tatemichi SR. Breast cancer-related lymphedema: women's experiences with an underestimated condition. Can Fam Physician 2005; 51: $246-247$.

[50] Paskett ED, Stark N. Lymphedema: knowledge, treatment, and impact among breast cancer survivors. Breast J 2000; 6(6): 373-378.

[51] Moffatt CJ, Franks PJ, Doherty DC, Williams AF, Badger C, Jeffs E, Bosanquet N, Mortimer PS. Lymphedema: an underestimated health problem. QJM 2003; 96(10): 731738.

[52] Verbelen H, Gebruers N, Eeckhout FM, Verlinden K, Tjalma W. Shoulder and arm morbidity in sentinel node-negative breast cancer patients: a systematic review. Breast Cancer Res Treat 2014; 144(1): 21-31. 


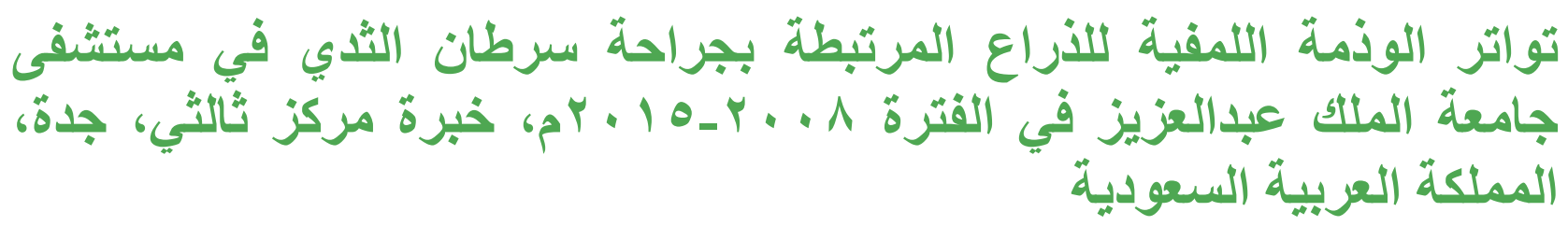

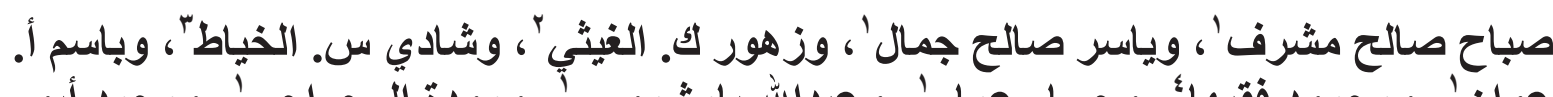

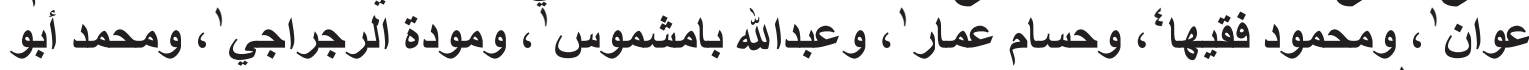

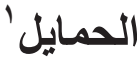

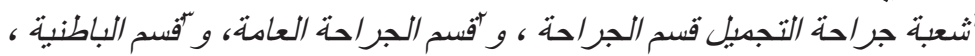

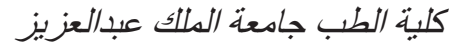

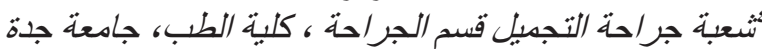
جدة - المعلكة العربية السعودية

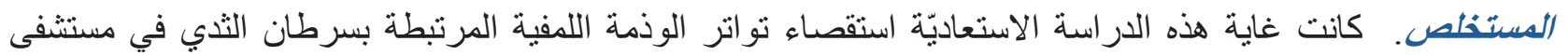

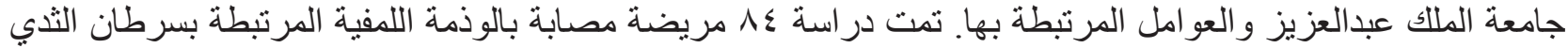

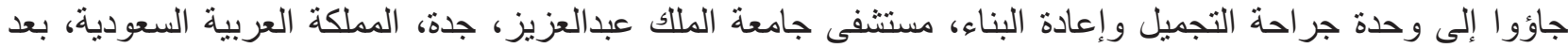

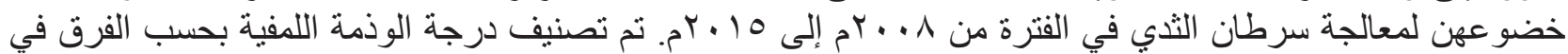

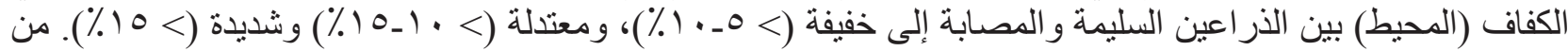

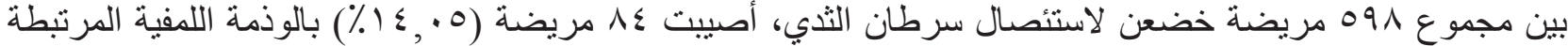

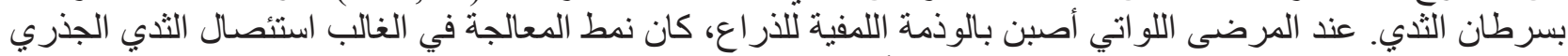

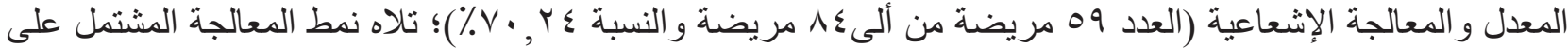

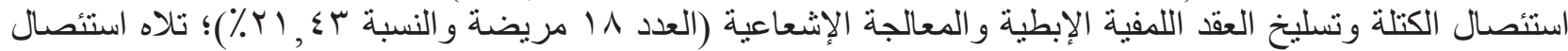

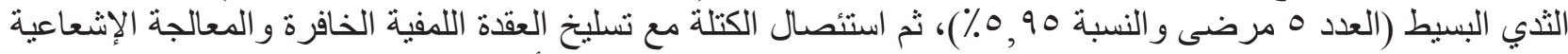

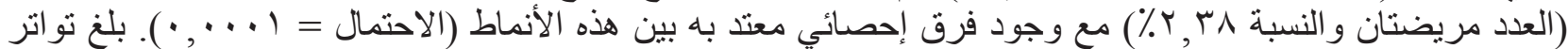

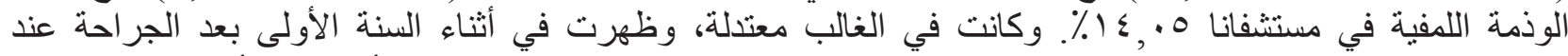

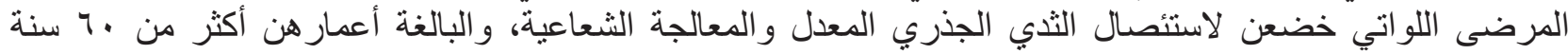
و السمينات. 